See Article page e447.

\section{Commentary: No distal anastomosis and negligible circulatory arrest time during frozen elephant trunk technique: More evidence is needed}

\author{
Ourania Preventza, MD, ${ }^{\mathrm{a}, \mathrm{b}}$ and Kim I. de la Cruz, $\mathrm{MD}^{\mathrm{c}}$
}

Various brain protection strategies, including hypothermia and antegrade or retrograde cerebral perfusion, have been advocated for aortic arch surgery. Expeditious repair with strategic steps to minimize the time spent under circulatory arrest also is important, as endorsed by experienced aortic surgeons. ${ }^{1}$

$\mathrm{Li}$ and colleagues ${ }^{2}$ present a strategy for shortening the hypothermic circulatory arrest time during aortic arch replacement in the setting of acute type A aortic dissection. Their approach includes a modified frozen elephant trunk (FET) technique with no distal anastomosis and multiple cannulation sites (femoral artery, right axillary artery, and left subclavian artery) connected to 1 trifurcated line. The femoral and right axillary arteries, which are cannulated directly, are used for systemic cooling. The left subclavian artery is cannulated to address a possible incomplete circle of Willis and to optimize blood flow into the left hemisphere. ${ }^{2}$

For the FET technique, the authors use a $6.5-\mathrm{cm}$ proximal unstented Dacron graft (MicroPort Medical, Shanghai, China) deployed into the descending thoracic aorta with no distal anastomosis. After graft deployment, the distal arch with the proximal unstented FET graft is clamped, and circulatory arrest is terminated. The reported circulatory arrest time is approximately 2.6 minutes, and cerebral perfusion time is approximately 8 to 9 minutes. ${ }^{2}$

\footnotetext{
From the a Division of Cardiothoracic Surgery, Michael E. DeBakey Department of Surgery, Baylor College of Medicine, Houston, Tex; ' Department of Cardiovascular Surgery, Texas Heart Institute, Houston, Tex; and ${ }^{\mathrm{c}}$ Department of Cardiothoracic Surgery, Methodist Hospital-San Antonio, San Antonio, Tex.

Disclosures: The authors reported no conflicts of interest.

The Journal policy requires editors and reviewers to disclose conflicts of interest and to decline handling or reviewing manuscripts for which they may have a conflict of interest. The editors and reviewers of this article have no conflicts of interest.

Received for publication Dec 4, 2020; revisions received Dec 4, 2020; accepted for publication Dec 5, 2020; available ahead of print Jan 5, 2021.

Address for reprints: Ourania Preventza, MD, Division of Cardiothoracic Surgery, Michael E. DeBakey Department of Surgery, Baylor College of Medicine, One Baylor Plaza, BCM 390, Houston, TX 77030 (E-mail: preventz@bcm.edu).

J Thorac Cardiovasc Surg 2021;161:e453-4

$0022-5223 / \$ 36.00$

Copyright (c) 2020 by The American Association for Thoracic Surgery

https://doi.org/10.1016/j.jtcvs.2020.12.039
}

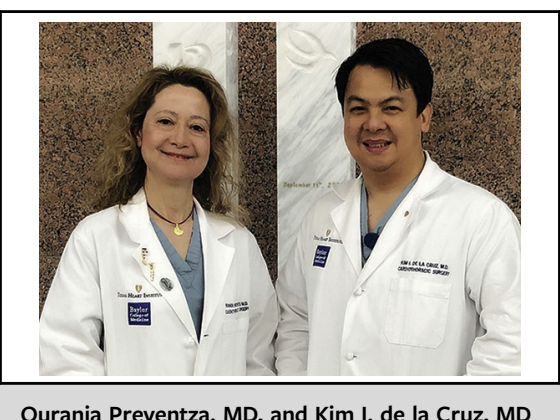

Ourania Preventza, MD, and Kim I. de la Cruz, MD

$$
\begin{aligned}
& \text { CENTRAL MESSAGE } \\
& \text { In the setting of an acute type A } \\
& \text { aortic dissection, the patient's } \\
& \text { specific condition and anatomy } \\
& \text { should guide us as to the specific } \\
& \text { surgical strategy. }
\end{aligned}
$$

This strategy is interesting, but to be successful it requires favorable body habitus and favorable anatomy of the aortic arch and proximal descending thoracic aorta. In our experience, clamping the distal arch in these patients is usually difficult, and additional dissection of already fragile tissues is required. Favorable anatomy (ie, a normal-sized distal arch and proximal descending thoracic aorta and arch vessels that are not "too deep" to be reached surgically) is key for being able to clamp the distal arch. Further, the 3-site cannulation scheme may be not suitable for hemodynamically unstable patients, and exposing the left subclavian artery can be difficult in large or obese patients. Although the authors state that exposing 3 cannulation sites does not add much time, every incision necessitating exposure can be a potential bleeding source and increases the overall operating time in patients who already have significant risk for morbidity and mortality.

Regarding not having a distal anastomosis, as surgeons, we have difficulty imagining that no retrograde bleeding will occur around the FET once perfusion from the femoral artery cannulation site is reestablished and the distal arch is clamped; the authors rely on the FET's radial force on the aortic wall, in conjunction with the aortic clamp (if placed), to prevent the blood retrograde from invading the surgical field.

Undoubtedly, the authors' approach ${ }^{2}$ may be worth considering for some patients-for example, a younger individual whose aorta dissects first without previous aortic dilation and who has a completely normal distal arch and proximal descending thoracic aorta. As the authors acquire 
more experience with this technique, we expect them to enlighten us with additional insights and details about its efficacy and durability. Time will tell.

Until then, we may continue to use our classic and modified FET techniques based on individual patient characteristics. ${ }^{3}$

The authors thank Jeanie F. Woodruff, BS, ELS, of the Department of Scientific Publications at the Texas Heart Institute, for providing editorial support.

\section{References}

1. Matalanis G, Galvin SD. "Branch-first" continuous perfusion aortic arch replacement and its role in intra-operative cerebral protection. Ann Cardiothorac Surg. 2013;2:194-201.

2. Li Q, Ma WG, Sun LZ. Optimization of the total arch replacement technique: left subclavian perfusion with sequential aortic reconstruction. J Thorac Cardiovasc Surg. 2021;161:e447-51.

3. Preventza O, Garcia A, Cooley DA, Haywood-Watson RJ, Simpson K, Bakaeen FG, et al. Total aortic arch replacement: a comparative study of zone 0 hybrid arch exclusion versus traditional open repair. $J$ Thorac Cardiovasc Surg. 2015;150:1591-8; discussion 1598-600.
See Article page e447.

\section{Commentary: Doing the distal more proximal}

\author{
Anthony L. Estrera, MD
}

Surgical reconstruction of the transverse aortic arch is burdened with the potential for debilitating complications and death. Graft reconstruction of the arch (with or without aortic root) is even more challenging in the setting of acute type A aortic dissection. To reduce these risks, surgeons have developed techniques and approaches with 2 goals: minimize organ ischemia, and reduce bleeding.

$\mathrm{Li}$ and colleagues ${ }^{1}$ describe their technique of the frozen elephant trunk procedure for total arch replacement in the setting of type A aortic dissection. The authors use a trifurcated arterial line circuit to perfuse the common femoral artery and left and right axillary arteries. Depending on the sequence of clamping, arterial perfusion is maintained to all organs with only minimal interruption (about 2 minutes) when the frozen elephant trunk is deployed.

From the Department of Cardiothoracic and Vascular Surgery, McGovern Medical School at The University of Texas Health Science Center at Houston and Memorial Hermann Hospital, Houston, Tex.

Disclosures: Dr Estrera is a consultant for WL Gore \& Associates.

The Journal policy requires editors and reviewers to disclose conflicts of interest and to decline handling or reviewing manuscripts for which they may have a conflict of interest. The editors and reviewers of this article have no conflicts of interest.

Received for publication Feb 12, 2021; revisions received Feb 12, 2021; accepted for publication Feb 17, 2021; available ahead of print Feb 26, 2021.

Address for reprints: Anthony L. Estrera, MD, Department of Cardiothoracic and Vascular Surgery, McGovern Medical School at The University of Texas Health Science Center at Houston, 6400 Fannin St, Suite 2850, Houston, TX 77030 (E-mail: Anthony.L.Estrera@uth.tmc.edu).

J Thorac Cardiovasc Surg 2021;161:e454-5

$0022-5223 / \$ 36.00$

Copyright (c) 2021 by The American Association for Thoracic Surgery

https://doi.org/10.1016/j.jtcvs.2021.02.071
Check for updates

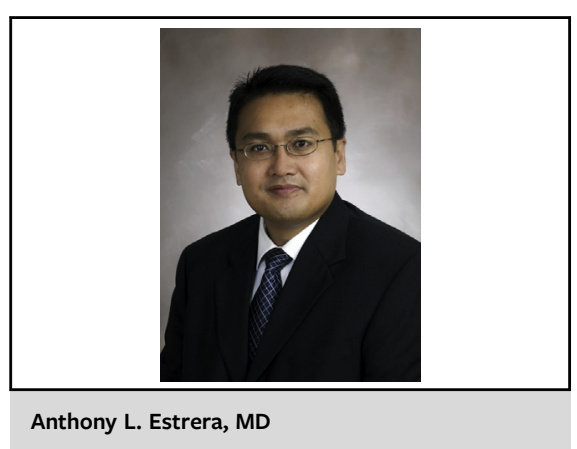

CENTRAL MESSAGE

The authors describe an innova-

tive technique for total arch

replacement in the setting of

type A aortic dissection. A larger

series is required before wide

adoption is recommended.

The aortic crossclamp is placed onto the frozen elephant trunk prosthesis and femoral perfusion is reinitiated. This approach is not novel as it has been described previously. At any rate, they address the first goal of minimizing organ ischemia.

What was interesting in their approach was the management of the great arteries. The left subclavian artery was ligated proximally_-and would be bypassed after completion of the aortic reconstruction. The left common carotid and innominate arteries were left in situ, and sutured to a longitudinal opening on the polyethylene terephthalate portion of the elephant trunk graft with the native aortic tissue left in place. For lack of a better term, this may be considered an inclusion technique for this island anastomosis. The inclusion approach, according to the authors, reduced bleeding from that anastomosis (goal 2). 